\title{
Study of the Stress-Strain State in the Mined Potassium Massif with Inclined Bedding
}

\author{
M. A. Zhuravkov, A. V. Krupoderov, O. L. Konovalov \\ Department of Theoretical and Applied Mechanics, Velarusian State University, Minsk, Belarus \\ Email: zhuravkov@bsu.by, krupoderov@tut.by, olegminsk@tut.by
}

Received September 28, 2013; revised October 28, 2013; accepted November 5, 2013

Copyright (C) 2014 M. A. Zhuravkov et al. This is an open access article distributed under the Creative Commons Attribution License, which permits unrestricted use, distribution, and reproduction in any medium, provided the original work is properly cited. In accordance of the Creative Commons Attribution License all Copyrights (C) 2014 are reserved for SCIRP and the owner of the intellectual property M. A. Zhuravkov et al. All Copyright (C) 2014 are guarded by law and by SCIRP as a guardian.

\section{ABSTRACT}

This paper presents results which concern regularities of propagation of discontinuous zones from mined-out space in rock massif with inclined bedding structure. The dependencies of maximal height of these zones from the inclination angle of productive beds were found. The mechanical model of rock massif was chosen as viscoelastic and transversely isotropic. Finite element method was used for calculation performing. Coulumb-Mohr and maximal elongation criteria were used for determination of discontinuous zones.

\section{KEYWORDS}

\section{Rock Massif; Discontinuous Zones Height; Stress-Strain State; Inclination Angle}

\section{Introduction}

For predicting the deformation processes in the rock's massif it is important to develop rock's massif models that adequately describe its state and behavior depending on the ultimate objectives of the study. When this is to be done, it is very difficult to allow for the time-varying behavior of the stress-strain state in the massif because of a great variety of influencing factors. The main difficulty is associated with the non-uniform, block structure of the massif. The availability of the systems of small and large block fractures, fracture rupture and large tectonic breaches in the massif, a different orientation of these structural disturbances with respect to the geometric parameters of underground structures, as well as a diversity of fracture fillers and contact conditions of fractures in the massif make the account of structure non-uniformities very intricate.

The presence of the natural hierarchic structure in the rock's strata due to the available surfaces and geological breaches, as well as due to inclined bedding, defines complex deformation processes in rock's massifs as a result of both natural geophysical processes and mancaused sources.

As one of the primary targets in studies of deformation processes in a mined massif with inclined bedding the following can be defined:

1) Depending on the mining schemes of rock's strata (spatial and time factors) to determine the main characteristic zones in a mined massif with inclined bedding and to establish the special features of their formation unlike a massif with horizontal bedding;

2) Investigation the process of a subsidence trough formation during mining works.

The present work contains the research results for definition of the special features of the propagation of discontinuous zones in a mined potassium massif with inclined bedding. According to the above-mentioned two major tasks, the solution of the formulated problem is associated both with studying the strain state of the rock's strata and with revealing the characteristic zones in the massif from the mining depth to the earth's surface.

Special attention should be paid to solving such important tasks as the dimensioning of the zones of increased stress and, specially, tensile stresses on nonuniformities; the assessment of possible man-caused fractured zones; the assessment of the characteristic sizes of fractures and blocks into which the space in the vicinity of the mine can be subdivided; the substantiation of possible means of reducing the above-mentioned dan- 
gerous effects.

The most significant factors which should be taken into account in constructing a geomechanical model for the massif state throughout its entire strata are the following:

1) Structural-geological regional features of rock's strata;

2) Effective physical-mechanical properties of rock's strata;

3) Man-caused impact characteristics (mining plans);

4) Natural and induced stress states of massif;

5) Characteristic areas in the massif found through the strain and stress states.

It should be noted that a lot of works [1-5] are concerned with considering the problems for definition of regularities of discontinuity zones and subsidence in rock's massifs. However, we did not meet the works dealing with the definition, for example, the extent of these zones from the mining as a function of the slope angle of potash and salt beds. Yet, this task is very important in predicting a required depth of water-protective strata on salt and potash deposits and in making recommendations on the protection of mines from flooding. Owing to this, the influence of the slope angle of productive beds on the height (extent) of possible man-caused fractured zones due to the mining of a single longwall is assessed in the present work.

\section{Echoice of the Massif Mechanical Behavior Model}

For deposits of layered structure and flat occurrence of enclosing rocks the deformation processes develop from the mining depth to the earth's surface, followed by a successive exfoliation of a set of beds and a subsequent failure of some of them. In the case of inclined bedding the deformation process of rock's strata can have some distinctive features.

For rock's massifs when mining at large depths, besides the rock's massif compressive, tensile, bending strength, as well as the elastic properties of the massif, the massif cohesion and friction must be taken into consideration, too. The last condition is due to the fact that as it follows from the strength certificate, at the rocks deformations the friction influence increases and the cohesion influence decreases with increasing loads.

The existence of sliding surfaces must be taken into account when computational model schemes for the geomechanical state in the vicinity of the underground mining are constructed.

Note. The position of sliding surfaces depends on the mining type and the massif stress state form.

As a result of our earlier studies it is shown (see, for example, [6-9]) that the behavior of potassium massifs is correctly described by the viscoelastic transversal-isotropic model. The fundamental governing equations and the relations of the mentioned model are outlined, for example, in works [6-10].

It should be noted that the consideration of the rock's massif as a transversal-isotropic medium is proved to be correct from the physical viewpoint. This depends on the fact that the massif is a multi-bed medium with different contact conditions of beds. It seems impossible to take into account all these conditions directly in the computational model. At the same time, the adoption of the transversal-isotropic model enables one to allow for the rock's bedding at the stage of constructing a model. It can be emphasized that the transversal-isotropic model of the rock's massif is actively employed and a wide use in a literature [1-5,10].

In work [10] it is shown that the shear modulus in the perpendicular direction to the rock's bedding exerts a main influence on the characteristics of the forming subsidence trough for rock's massifs with bedding. If in the mentioned direction the shear modulus values found in laboratory conditions are absent, then it is recommended to take its value as equal to $5 \%-15 \%$ of the shear modulus value in the rock bedding direction.

Based on the previously performed numerical experiments made within the framework of the previous researches (see, for example, [6-8]) it was established that for the considered class of problems it is enough to choose several (namely, three) basic sets of rock's beds with different physical-mechanical parameters. The conventionally selected three basic sets of rock's beds can be called sedimentary bed, argillo-marlaceous strata (AMS) and salt bed.

The physical-mechanical properties of the selected sets of rock's beds are cited in Table 1 [11].

It should be noted that for each selected set of rock's beds the anisotropy direction is different. So for the set of salt beds this direction is perpendicular to the direction of the mined space. For the set of the AMS bed, the bed occurrence direction was taken at the angle that is twice less than that of the salt bed occurrence. The sedimentary bed was taken to be horizontal.

The system of resolving equations was built, assuming that the statement of the model problem was two-dimensional. In this case this is relevant, since consideration is made of the longwall, whose length exceeds its width several times and the section at the center of a single

Table 1. Values of the physical-mechanical parameters.

\begin{tabular}{ccccc}
\hline \multirow{2}{*}{ Bed } & \multicolumn{4}{c}{ Physical-mechanical parameters } \\
\cline { 2 - 5 } & $\mathrm{E}_{1}(\mathrm{~Pa})$ & $v_{2}$ & $\mathrm{G}_{2}(\mathrm{~Pa})$ & $\rho\left(\mathrm{kg} / \mathrm{m}^{2}\right)$ \\
\hline Sedimentary & $10^{9}$ & 0.3 & $0.05 \times 10^{9}$ & 2200 \\
AMS & $7 \times 10^{9}$ & 0.3 & $0.4 \times 10^{9}$ & 2400 \\
Salt & $15 \times 10^{9}$ & 0.3 & $0.86 \times 10^{9}$ & 2400 \\
\hline
\end{tabular}


longwall is most dangerous.

Problems were solved using the finite-element software TOCHNOG.

\section{Description of the Simulation Domain Geometry}

Based on the initial data on geological sections, the example of one of which is shown in Figure 1, the following geometry of the model is chosen (Figure 2).

The mined space was assigned by removing the elements that are "presence" in this domain. The mined space parameters were chosen as follows:

1) Difference between the low mark of the salt roof and the mined space center: $\Delta H=100 \mathrm{~m} ; 200 \mathrm{~m} ; 300 \mathrm{~m}$;

2) Slope angle of the mined space:

$\alpha=0^{\circ} ; 5^{\circ} ; 10^{\circ} ; 15^{\circ} ; 20^{\circ} ; 25^{\circ}$.

The mined space pattern is shown in Figure 3.

\section{Criteria for Allocation of Dangerous Zones in the Mined Massif}

The behavior of geomaterials and rock's massifs as a whole has its features in comparison with other types of deformable media. Among such characteristics of geomaterials it is first necessary to emphasize that the tensile and compressive strength limits of geomaterials are substantially different.

With regard to the deformation features of the mined rock's strata the characteristic areas in the massif were defined using the following criteria:

1) The maximum linear strain criteria (investigation of the conditions for macrofracture formation in the zone of smooth beds bending) [12] that are written in terms of the strain state

$$
F\left(\varepsilon_{1}, \varepsilon_{3}\right)=\left\{\begin{array}{l}
\varepsilon_{1} \leq \varepsilon_{\lim }^{\text {ext }} \\
\left|\varepsilon_{3}\right| \leq \varepsilon_{\text {lim }}^{\text {pres }}
\end{array}\right.
$$

where $\varepsilon_{\lim }^{\text {ext }}$ is the ultimate tensile strain corresponding to the moment of the elasticity limit (positive value); $\varepsilon_{\lim }^{\text {pres }}$ is the ultimate compressive strain corresponding to the moment of the elasticity limit (negative value);

2) The Coulomb-Mohr criterion [12]

$$
\frac{\sigma_{1}-\sigma_{3}}{2}+\frac{\sigma_{1}+\sigma_{3}}{2} \sin \phi<C \cos \phi
$$

where $\sigma_{1}, \sigma_{3}$, are the maximum and minimum principal stress values, respectively; $C$ is the rock cohesion; $\phi$ is the internal friction angle.

So, to construct possible man-caused fractured zones in the mined potassium salt massif with inclined bedding, the criterion of maximum linear/horizontal strains in form (1) and the Coulomb-Mohr criterion in form (2) were used.

\section{Basic Results of Numerical Simulation}

The procedure of solving the problem on the selection of characteristic areas in the massif represented the iteration solution sequence of mechanics problems on the behavior of an elastic deformable rigid body and the definetion of new effective elastic characteristics at each step.

At the first stage, using the data $[13,14]$ on the pro-

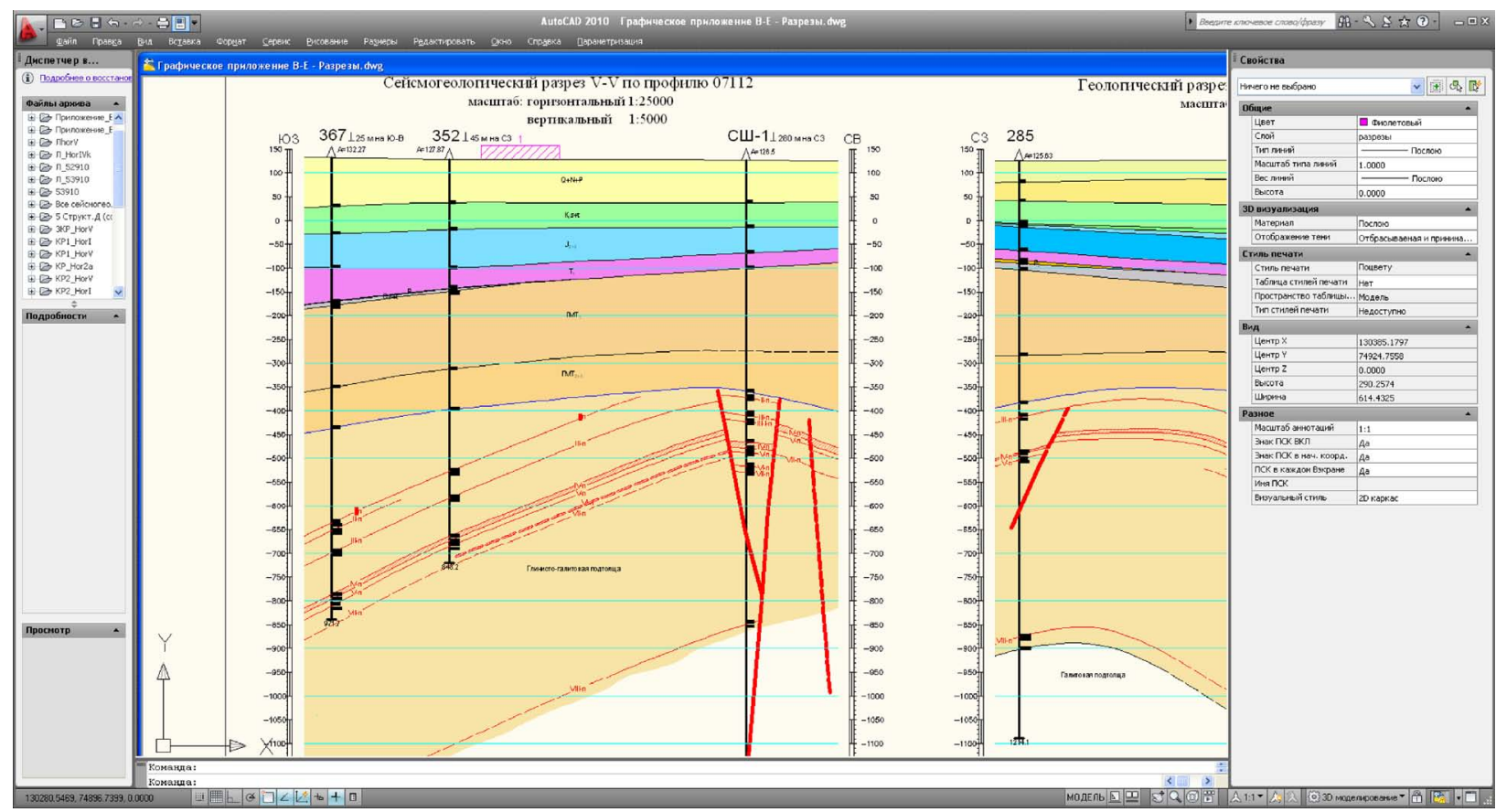

Figure 1. Section geometry. 


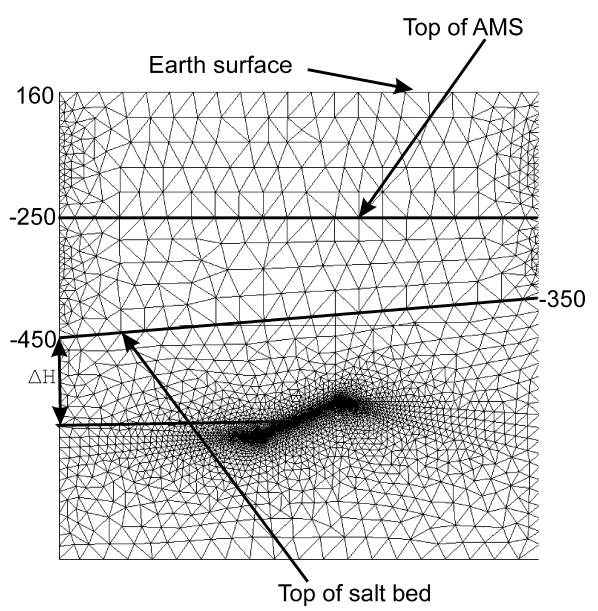

Figure 2. Section geometry.

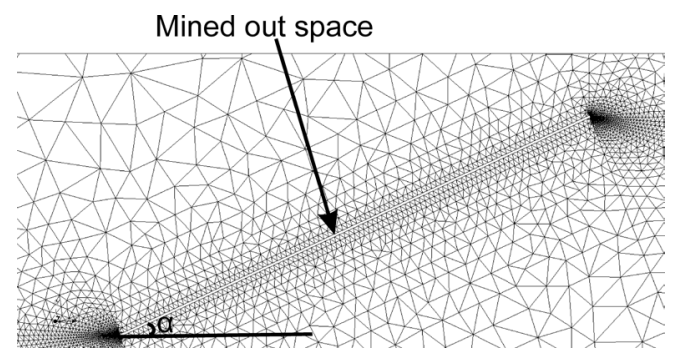

Figure 3. Mined space pattern.

posed occurrence heights of man-caused water supply fractures on the Starobin's potash deposit the quantity $\varepsilon_{\lim }^{\text {ext }}$ was found.

It is known that the maximum occurrence height of man-caused water supply fractures on the Starobin's deposit is approximate $120 \mathrm{~m}$. It is also known that the slope angle of bedding varies from 0 to 100 . Ultimate strain values can be taken after solving the inverse problem. To do this, define maximum strains in the line being at $120 \mathrm{~m}$ from its center at the angle of the mined space equal to 0 and 10 degree. Graphs the horizontal and principal strains at the slope angles of 0 and 10 degree are shown in Figures 4 and 5.

From the presented plots it is seen that the value of ultimate strains is $\varepsilon_{\lim }^{\text {ext }}=3.5 * 10^{-3}$.

In order to use the Coulomb-Mohr criterion, based on [11], the following strength parameters of the massif were chosen: $C=2 \mathrm{MPa}, \phi=0.77 \mathrm{rad}$.

At the first stage of numerical experiments, computations were made to assess the height of the massif discontinuity zone at different slope angles of the mined bed according to the maximum linear strain criterion.

Some computation results for different values of discontinuity zones obtained according to the maximum linear strain criteria are shown in Figures 6-9. White color denotes the discontinuity zones according to this criterion at different slope angles of a single longwall and at different depths of the mined space center.

Tables 2-7 contain the computation results for the dangerous zone depths determined using the maximum linear strain criteria. In this case, the distances to the corresponding points were determined according to Figure 10.

At that, the variation coefficients of the height were computed with respect to the zone height at a bed slope angle of 10 degree.

The analysis of the obtained results shows that if the distances of the mined space center from the salt roof are $100 \mathrm{~m}$ and more, then the mining poses a great risk since in this case, the possible man-caused fractured zones are already crossing the salt roof and penetrate into the argillo-marlaceous strata.

As a result of numerical simulations it is found that the height of possible man-caused fractured zones from the mining does not depend on the mining depth. So, the maximum value of the man-caused fractured zones coefficient increase in computations from the lower edge of the mined space is 1.12. Moreover, the analysis of the height variations of a fractured zone from the mining in the vicinity of the upper edge has yielded that the height of this zone decreases. The same can be said when the height is computed from the mined space center.

At the next research stage, the discontinuity zones according to Coulomb-Mohr criterion (2) were determined. Figures 11-14 demonstrate the computation results. The discontinuity zones according to (2) are made in white.

Tables 8-13 contain numerical results for the distribution of heights of possible man-caused fractured zones from the mining obtained with the use of the Coulomb-Mohr criterion at the basic variations of the mining parameters.

The analysis of the obtained results with the use the maximum linear strain criterion showed that if the distances of the mined space center from the salt roof are $100 \mathrm{~m}$ and more, then the mining poses a great risk since in this case, the possible man-caused fractured zones are already crossing the salt roof and penetrate into the argillo-marlaceous strata. In this case it was also found that the penetration height of possible man-caused fractured zones insignificantly depends on the mining depth.

Of interest is the fact that the maximum increase coefficient of the height of man-caused fractured zones from the mining in computations from the lower edge of the mined space in this case is 0.98 . Thus, the height of the dangerous zone from the lower edge does not increase, but decreases. The same may be said when the height of the discontinuity zone computed from the mined space center and from the upper edge of the longwall. In this case, there is a more substantial decrease in the coefficients of increase of the height of the mentioned zone from the mining.

It is also established that in the case of horizontal and 


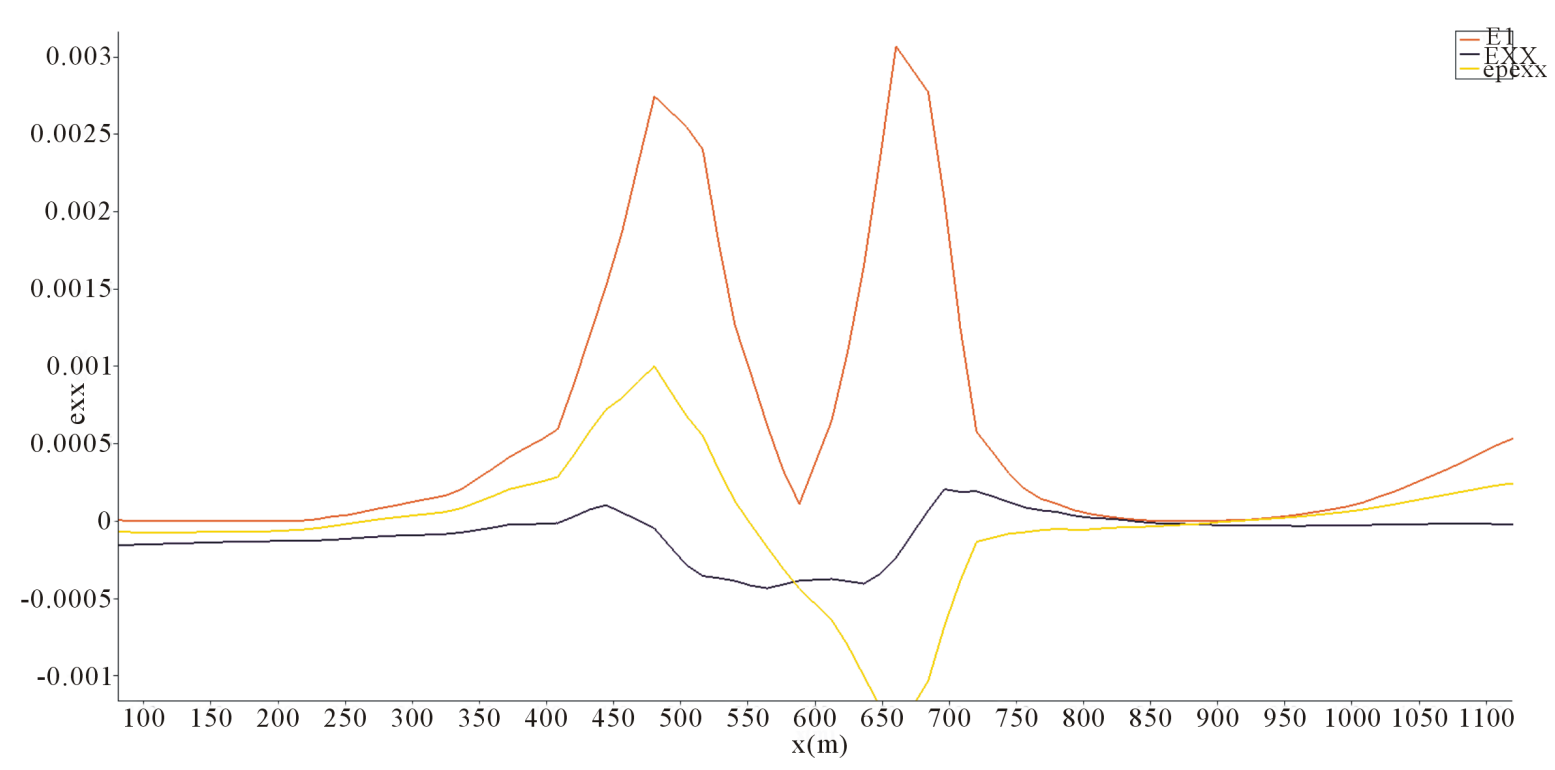

Figure 4. Strain at a distance of $120 \mathrm{~m}$ from the mined space center at a mined space slope angle of $10^{\circ}$.

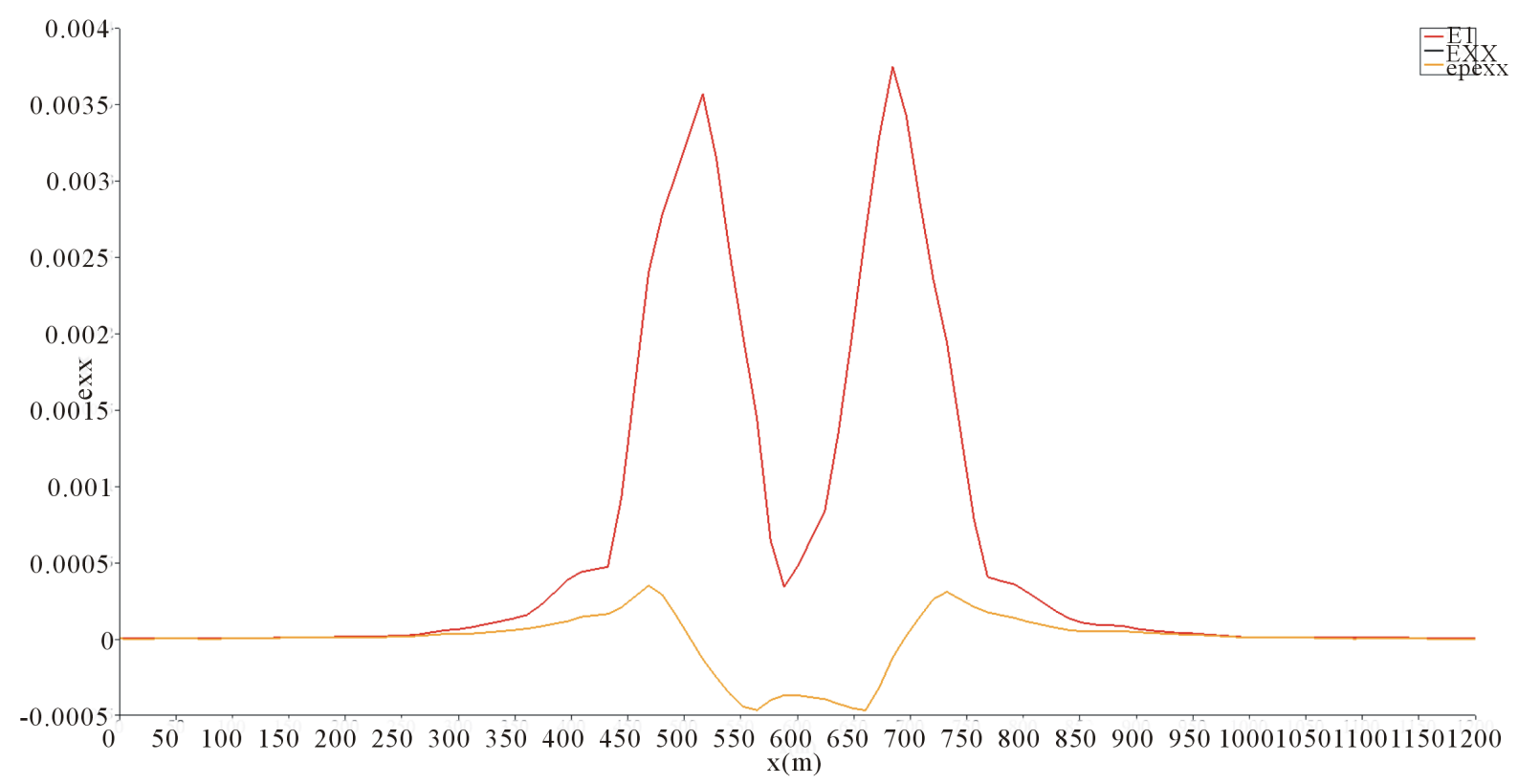

Figure 5. Strain at a distance of $120 \mathrm{~m}$ from the mined space center at a mined space slope angle of $\mathbf{0}$ deg.

Table 2. Heights of possible man-caused fractured zones from the mining at a mined space center depth of $710 \mathrm{~m}$ (the thickness of salt-bearing deposits above the mined space center is $\mathbf{1 0 0} \mathbf{~ m}$ ) according to the maximum linear strain criterion.

\begin{tabular}{cccccccc}
\hline \multirow{2}{*}{ Position } & \multicolumn{5}{c}{$\alpha$ (degree) } \\
\cline { 2 - 7 } & 0 & 5 & 10 & 15 & 20 & 25 \\
\hline From the lower edge & 167.79 & 176.51 & 171.1 & 149.44 & 152.74 & 160.23 \\
From the center & 167.79 & 167.79 & 153.74 & 123.55 & 118.54 & 117.97 \\
From the upper edge & 167.79 & 159.08 & 136.37 & 97.67 & 84.33 & 75.7 \\
\hline
\end{tabular}

flat occurrence of beds the main discontinuity zones are formed in the rock's strata above the edge zones of the mined space. In the case of a steeper occurrence of beds, possible man-caused fractured zones are formed already 


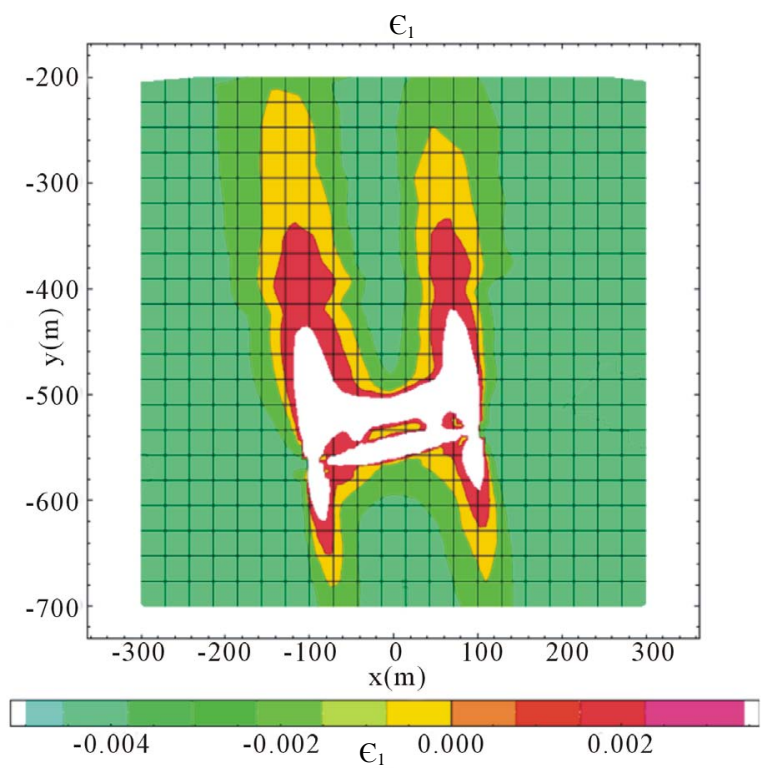

Figure 6. Possible man-caused fractured zones at a mined space slope angle of $10^{\circ}$ and at a mined space center depth of $710 \mathrm{~m}$ (the thickness of salt-bearing deposits above the center is $100 \mathrm{~m}$ ) according to the maximum linear strain criterion.

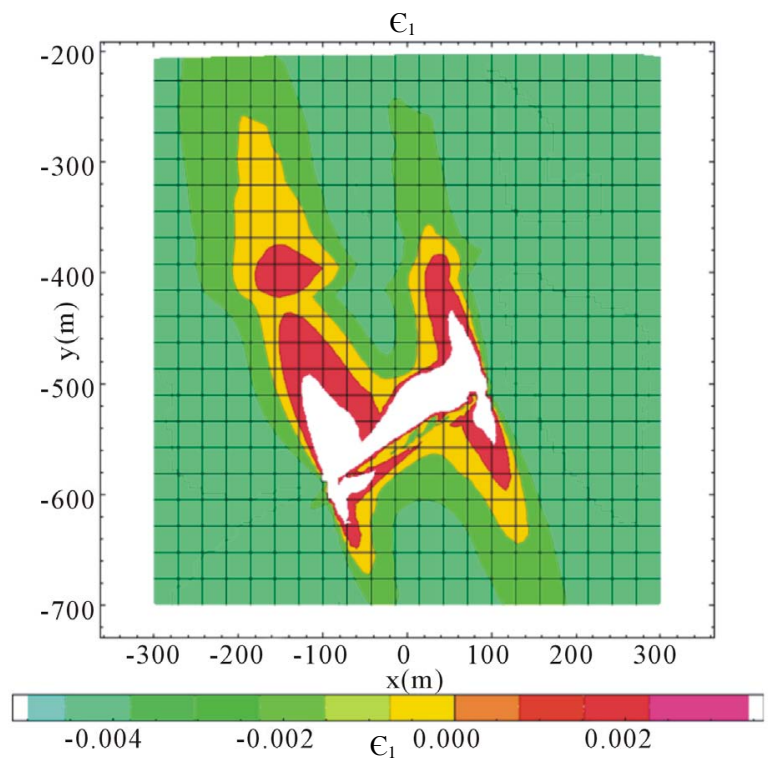

Figure 7. Possible man-caused fractured zones at a mined space slope angle of $25^{\circ}$ and at a mined space center depth of $710 \mathrm{~m}$ (the thickness of salt-bearing deposits above the center is $100 \mathrm{~m}$ ) according to the maximum linear strain criterion.

above the entire longwall.

\section{Conclusions}

Thus, the present work contains the results of research for assessment of the height of possible man-caused fractured zones from the mining at different depths of the

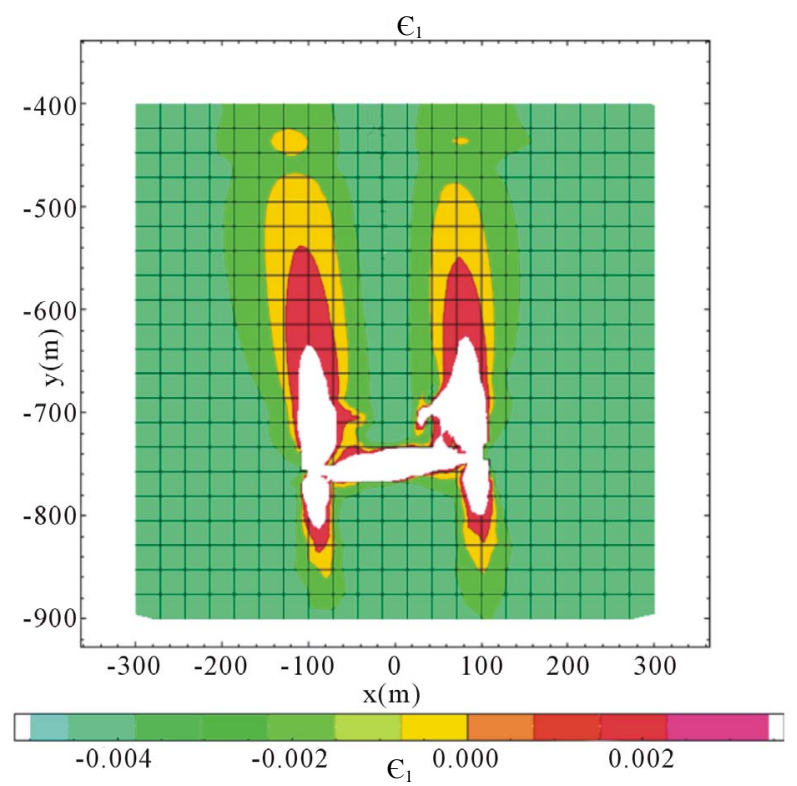

Figure 8. Possible man-caused fractured zones at a mined space slope angle of $5^{\circ}$ and at a mined space center depth of $910 \mathrm{~m}$ (the thickness of salt-bearing deposits above the center is $\mathbf{3 0 0} \mathbf{~ m}$ ) according to the maximum linear strain criterion.

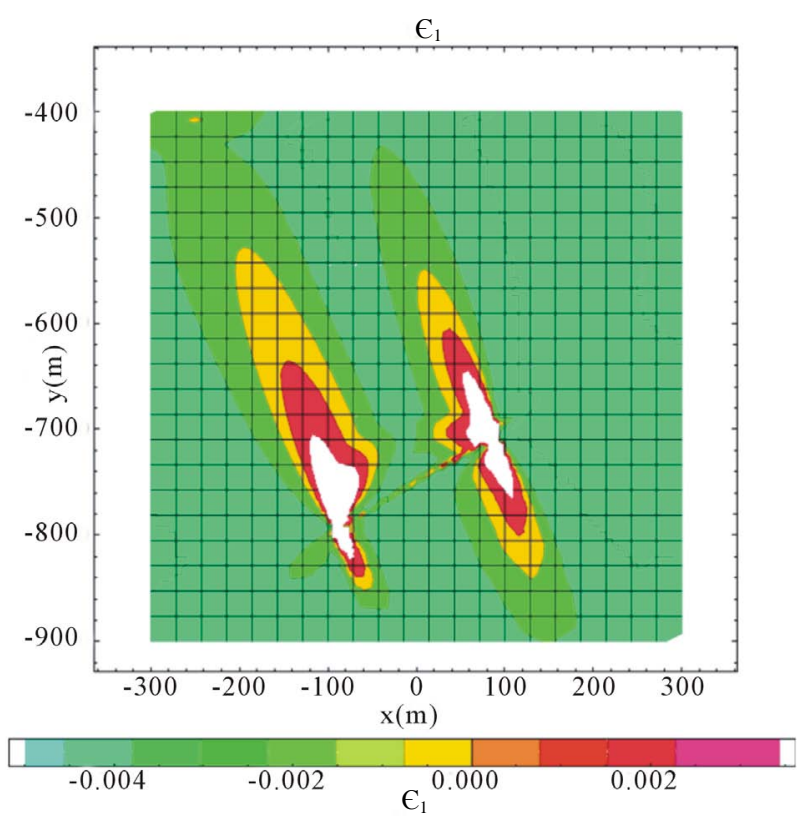

Figure 9. Possible man-caused fractured zones at a mined space slope angle of $25^{\circ}$ and at a mined space center depth of $910 \mathrm{~m}$ (the thickness of salt-bearing deposits above the center is $300 \mathrm{~m}$ ) according to the maximum linear strain criterion.

mined space and at different slope angles of the productive bed and, hence, at different slope angles of the mined space. The analysis is made with the use of the maximum linear strain criteria and the Coulomb-Mohr criteria that finds a wide use in geomechanics to analyze 
the discontinuity zones in the rock's massif.

At the first research stage, by solving the inverse

$\mathrm{H}$ from the upper edge

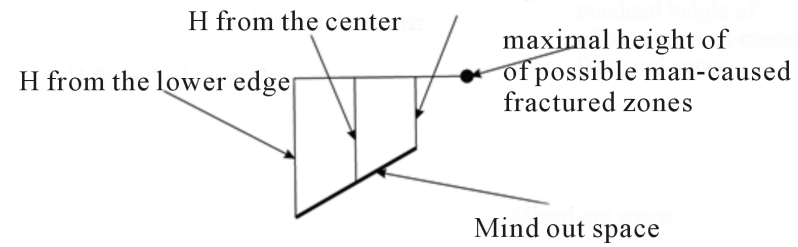

Figure 10. Computation of a possible man-caused fractured zone height.
Table 3. Variation coefficients of the possible man-caused fractured zones height from the mining at a mined space center depth of $710 \mathrm{~m}$ (the thickness of salt-bearing deposits above the mined space center is 100) according to the maximum linear strain criterion.

\begin{tabular}{ccccc}
\hline \multirow{2}{*}{ Position } & \multicolumn{4}{c}{$\alpha$ (degree) } \\
\cline { 2 - 5 } & 10 & 15 & 20 & 25 \\
\hline From the lower edge & 1 & 0.87 & 0.89 & 0.94 \\
From the center & 1 & 0.8 & 0.77 & 0.77 \\
From the upper edge & 1 & 0.72 & 0.62 & 0.56 \\
\hline
\end{tabular}

Table 4. Heights of possible man-caused fractured zones from the mining at a mined space center depth of $810 \mathrm{~m}$ (the thickness of salt-bearing deposits above the mined space center is $\mathbf{2 0 0} \mathbf{~ m}$ ) according to the maximum linear strain criterion.

\begin{tabular}{cccccccc}
\hline \multirow{2}{*}{ Position } & \multicolumn{9}{c}{$\alpha$ (degree) } \\
\cline { 2 - 7 } & 0 & 5 & 10 & 15 & 20 & 25 \\
\hline From the lower edge & 143.2 & 152.55 & 135.91 & 140.76 & 145.84 & 152.46 \\
From the center & 143.2 & 143.84 & 118.55 & 114.88 & 111.64 & 110.19 & 77.44 \\
From the upper edge & 143.2 & 135.12 & 101.18 & 88.99 & 67.93 \\
\hline
\end{tabular}

Table 5. Variation coefficients of the possible man-caused fractured zones height from the mining at a mined space center depth of $810 \mathrm{~m}$ (the thickness of salt-bearing deposits above the mined space center is 200) according to the maximum linear strain criterion.

\begin{tabular}{ccccc}
\hline & & & $\alpha$ (degree) \\
\cline { 2 - 5 } Position & 10 & 15 & 20 & 25 \\
\hline From the lower edge & 1 & 1.04 & 1.07 & 1.12 \\
From the center & 1 & 0.97 & 0.94 & 0.93 \\
From the upper edge & 1 & 0.88 & 0.77 & 0.67 \\
\hline
\end{tabular}

Table 6. Heights of possible man-caused fractured zones from the mining at a mined space center depth of $910 \mathrm{~m}$ (the thickness of salt-bearing deposits above the mined space center is $300 \mathrm{~m}$ ) according to the maximum linear strain criterion.

\begin{tabular}{cccccccc}
\hline \multirow{2}{*}{ Position } & \multicolumn{9}{c}{$\alpha$ (degree) } \\
\cline { 2 - 7 } & 0 & 5 & 10 & 15 & 20 & 25 \\
\hline From the lower edge & 120.8 & 134.48 & 133.47 & 141.08 & 142.94 & 149.3 \\
From the center & 120.8 & 125.77 & 116.1 & 115.2 & 108.74 & 107.04 & 74.53 \\
From the upper edge & 120.8 & 117.05 & 98.74 & 89.31 & 64.78 \\
\hline
\end{tabular}

Table 7. Variation coefficients of the possible man-caused fractured zones height from the mining at a mined space center depth of $910 \mathrm{~m}$ (the thickness of salt-bearing deposits above the mined space center is $\mathbf{3 0 0}$ ) according to the maximum linear strain criterion.

\begin{tabular}{|c|c|c|c|c|}
\hline \multirow{2}{*}{ Position } & \multicolumn{4}{|c|}{$\alpha$ (degree) } \\
\hline & 10 & 15 & 20 & 25 \\
\hline From the center & 1 & 0.99 & 0.94 & 0.92 \\
\hline From the upper edge & 1 & 0.9 & 0.75 & 0.66 \\
\hline
\end{tabular}


Table 8. Heights of possible man-caused fractured zones from the mining at a mined space center depth of $710 \mathrm{~m}$ (the thickness of salt-bearing deposits above the mined space center is $100 \mathrm{~m}$ ) according to the Coulomb-Mohr criterion.

\begin{tabular}{cccccccc}
\hline \multirow{2}{*}{ Position } & \multicolumn{7}{c}{$\alpha$ (degree) } \\
\cline { 2 - 7 } & 0 & 5 & 10 & 15 & 20 & 25 \\
\hline From the lower edge & 88.85 & 108.72 & 129.88 & 126.21 & 120.86 & 122.34 \\
From the center & 88.85 & 100 & 112.52 & 100.32 & 86.66 & 80.08 & 52.46 \\
From the upper edge & 88.85 & 91.28 & 95.15 & 74.44 & 37.82 \\
\hline
\end{tabular}

Table 9. Variation coefficients of the possible man-caused fractured zones height from the mining at a mined space center depth of $710 \mathrm{~m}$ (the thickness of salt-bearing deposits above the mined space center is 100) according to the Coulomb-Mohr criterion.

\begin{tabular}{ccccc}
\hline Position & \multicolumn{3}{c}{$\alpha$ (degree) } \\
\cline { 2 - 5 } & 10 & 15 & 20 & 25 \\
\hline From the lower edge & 1 & 0.97 & 0.93 & 0.94 \\
From the center & 1 & 0.89 & 0.77 & 0.71 \\
From the upper edge & 1 & 0.78 & 0.55 \\
\hline
\end{tabular}

Table 10. Heights of possible man-caused fractured zones from the mining at a mined space center depth of $810 \mathrm{~m}$ (the thickness of salt-bearing deposits above the mined space center is $\mathbf{2 0 0} \mathbf{~ m}$ ) according to the Coulomb-Mohr criterion.

\begin{tabular}{cccccccc}
\hline \multirow{2}{*}{ Position } & \multicolumn{5}{c}{$\alpha$ (degree) } \\
\cline { 2 - 7 } & 0 & 5 & 10 & 15 & 20 & 25 \\
\hline From the lower edge & 122.06 & 127.89 & 130.77 & 128.85 & 125.2 & 127.46 \\
From the center & 122.06 & 119.18 & 113.4 & 102.97 & 91 & 85.2 & 46.79 \\
From the upper edge & 122.06 & 110.46 & 96.04 & 77.09 & 56.94 \\
\hline
\end{tabular}

Table 11. Variation coefficients of the possible man-caused fractured zones height from the mining at a mined space center depth of $810 \mathrm{~m}$ (the thickness of salt-bearing deposits above the mined space center is 200) according to the Coulomb-Mohr criterion.

\begin{tabular}{ccccc}
\hline Position & \multicolumn{3}{c}{$\alpha$ (degree) } \\
\cline { 2 - 5 } & 10 & 15 & 20 & 0.97 \\
\hline From the lower edge & 1 & 0.99 & 0.96 & 0.8 \\
From the center & 1 & 0.91 & 0.95 & 0.45 \\
From the upper edge & 1 & 0.8 & 0.59 \\
\hline
\end{tabular}

Table 12. Heights of possible man-caused fractured zones from the mining at a mined space center depth of $910 \mathrm{~m}$ (the thickness of salt-bearing deposits above the mined space center is $300 \mathrm{~m}$ ) according to the Coulomb-Mohr criterion.

\begin{tabular}{|c|c|c|c|c|c|c|}
\hline \multirow{2}{*}{ Position } & \multicolumn{6}{|c|}{$\alpha$ (degree) } \\
\hline & 0 & 5 & 10 & 15 & 20 & 25 \\
\hline From the lower edge & 110.39 & 124.54 & 126.52 & 129.61 & 125.75 & 124.17 \\
\hline From the center & 110.39 & 115.83 & 109.16 & 103.72 & 91.55 & 81.9 \\
\hline
\end{tabular}


Table 13. Variation coefficients of the possible man-caused fractured zones height from the mining at a mined space center depth of $910 \mathrm{~m}$ (the thickness of salt-bearing deposits above the mined space center is $\mathbf{3 0 0}$ ) according to the Coulomb-Mohr criterion.

\begin{tabular}{ccccc}
\hline \multirow{2}{*}{ Position } & \multicolumn{4}{c}{$\alpha$ (degree) } \\
\cline { 2 - 5 } & 10 & 15 & 20 & 25 \\
\hline From the lower edge & 1 & 1.02 & 0.99 & 0.98 \\
From the center & 1 & 0.95 & 0.84 & 0.75 \\
From the upper edge & 1 & 0.85 & 0.62 & 0.43 \\
\hline
\end{tabular}

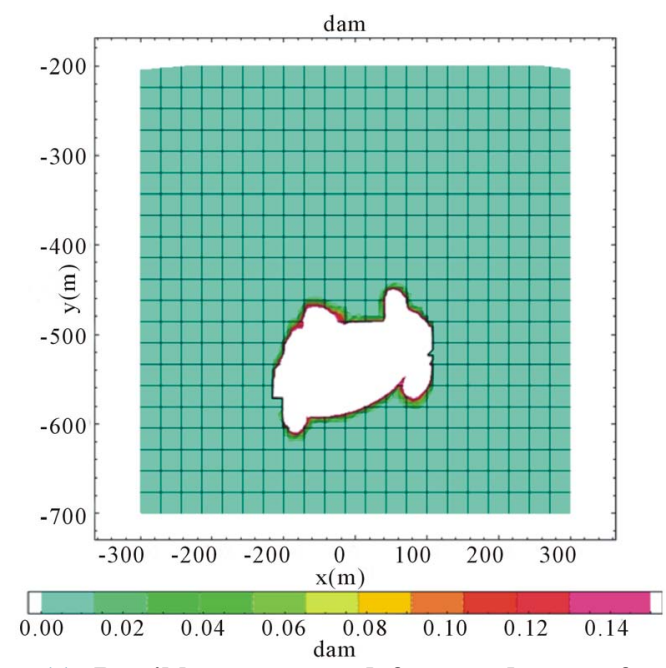

Figure 11. Possible man-caused fractured zones from the mining at a mined space slope angle of 15and at a mined space center depth of $710 \mathrm{~m}$ (the thickness of salt-bearing deposits above the mined space center is $100 \mathrm{~m}$ ) according to the Coulomb-Mohr criterion

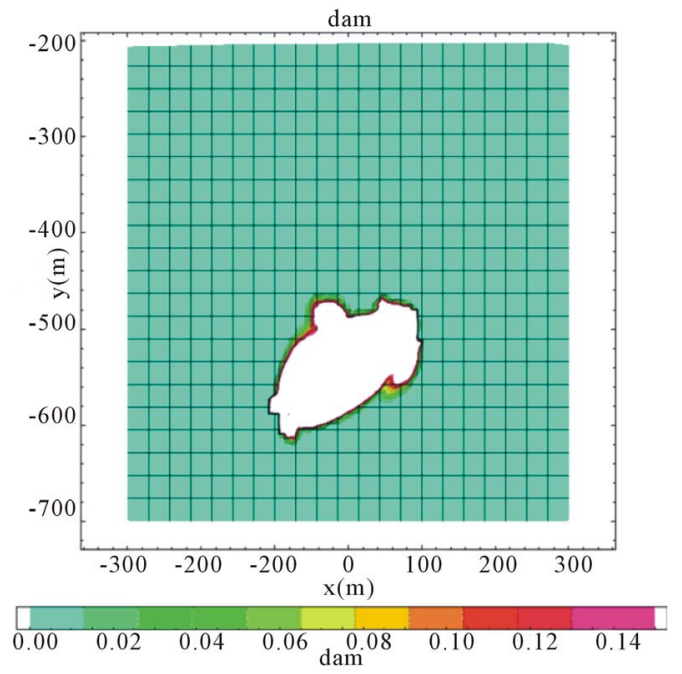

Figure 12. Possible man-caused fractured zones from the mining at a mined space slope angle of 25 and at a mined space center depth of $710 \mathrm{~m}$ (the thickness of salt-bearing deposits above the mined space center is $\mathbf{1 0 0} \mathrm{m}$ ) according to the Coulomb-Mohr criterion.

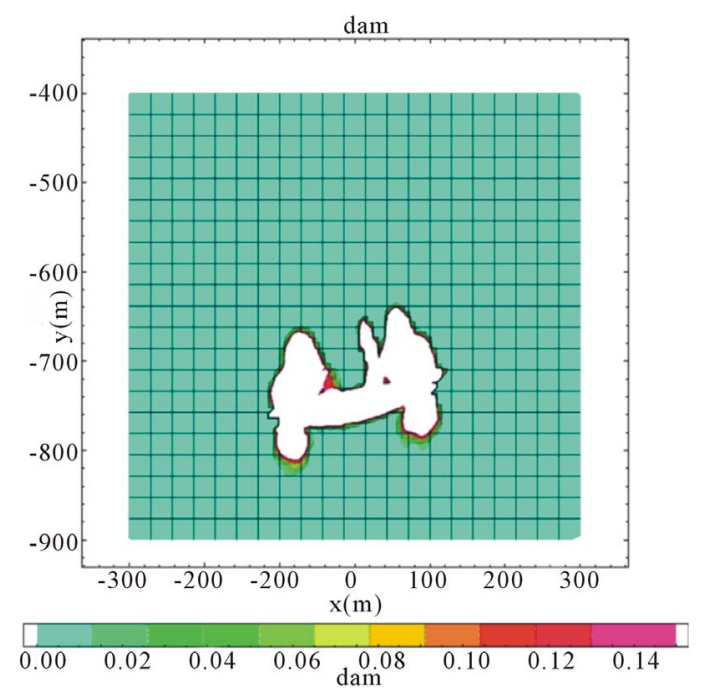

Figure 13. Possible man-caused fractured zones from the mining at a mined space slope angle of 10and at a mined space center depth of $910 \mathrm{~m}$ (the thickness of salt-bearing deposits above the mined space center is $300 \mathrm{~m}$ ) according to the Coulomb-Mohr criterion.

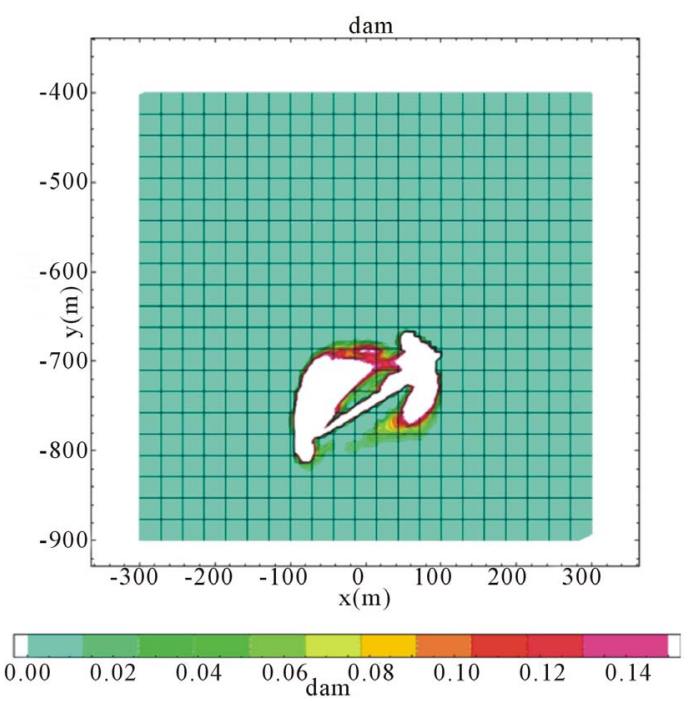

Figure 14. Possible man-caused fractured zones from the mining at a mined space slope angle of $25^{\circ}$ and at a mined space center depth of $910 \mathrm{~m}$ (the thickness of salt-bearing deposits above the mined space center is $300 \mathrm{~m}$ ) according to the Coulomb-Mohr criterion

problem and by analyzing the experimental data the ultimate quantities being a part of the mentioned criteria were found; in particular, these are ultimate tensile strains, internal friction angle and rock cohesion. Initial physical-mechanical characteristics of main beds were also selected. Mean depth values of these beds were revealed.

At the next stage, computations were made according to the selected characteristics and the stress-strain state of the rock's massif in the vicinity of the mined space was 
analyzed. According to the selected criteria, the potential possible man-caused fractured zones were found.

The obtained computation results made it possible to state that:

1) At a mined space center distance of $100 \mathrm{~m}$ and more from the potash roof the mining is very dangerous, since possible man-caused fractured zones in this case cross the salt roof and penetrate into the argillo-marlaceous strata. The above-said is valid for the both criteria;

2) The height of possible main-caused fractured zones from the mining insignificantly depends on the mined space depth;

3) When the maximum normal elongation criterion is used, the maximum increase coefficient of the height of massif discontinuity zones from the mining in computations from the lower edge of the mined space is 1.12, when the Coulomb-Mohr criterion is used -0.98 ;

4) When the height is computed from the mined space center and from the lava upper edge, the height of possible man-caused fractured zones decreases with increasing slope angle of the mined space;

5) In the case of horizontal and steep occurrence of beds, when the Coulomb-Mohr criteria are used, the main discontinuity zones are located in the edge zones of the mined space and in the case of steeper occurrence, possible man-caused violations are formed already above the entire single longwall;

6) When the maximum normal elongation criterion is used, the main discontinuity zones are located above the edge zones of the mined space.

\section{REFERENCES}

[1] M. Afsari Nejad, "Numerical Modelling of Inclined Seams,” Ph.D. Thesis, University of Nottingham, Nottingham, 1999.

[2] L. R. Alejano, P. Ramirez-Oyanguren and J. Taboada, "FDM Predictive Methodology for Subsidence Due Flat and Inclined Coal Seam Mining," International Journal of Rock Mechanics and Mining Sciences, Vol. 36, No. 4, 1999, pp. 475-491. http://dx.doi.org/10.1016/S0148-9062(99)00022-4

[3] X. L. Yao, D. J. Reddish and B. N. Whittaker, "NonLinear Finite Element Analysis of Surface Subsidence Arising from Inclined Seam Extraction,” International
Journal of Rock Mechanics and Mining Sciences \& Geomechanics, Vol. 30, No. 4, 1999, pp. 431-441. http://dx.doi.org/10.1016/0148-9062(93)91724-W

[4] N. Asfari and D. J. Reddish, "Numerical Modelling of Surface Subsidence Arising from Longwall Mining of Steeply Inclined Coal Seams," Proceedings of the II' $h$ Turkish Coal Congress, 10-12 June 1998, pp. 53-64.

[5] K. Shahriar and S. A. M. Arabzadeh, "Prediction of Surface Subsidence Due to Inclined Very Shallow Coal Seam Mining Using Fdm," Proceedings of Coal Operators' Conference, 2009, pp. 130-139.

[6] M. A. Zhuravkov, O. L. Konovalov and A. V. Krupoderov, "Methods of Computer Simulation of the Crustal Movements Influenced by Underground Mining,” Rock Mechanics, No. 1, 2008, pp. 3-11.

[7] M. A. Zhuravkov, O. L. Konovalov and A. V. Krupoderov, "Computer Simulation Technologies of Crustal Movements,” Surveying Bulletin, No. 4, 2008, pp. 31-37.

[8] M. A. Zhuravkov, O. L. Konovalov and A. V. Krupoderov, "Computer Simulation Technologies of Crustal Movements," Theoretical and Applied Mechanics, No. 24, 2009, pp. 142-147.

[9] M. A. Zhuravkov, O. L. Konovalov, A. V. Krupoderov, S. I. Bogdan and P. N. Prohorov, "Computer Numerical Simulation in Geomechanics,” BSU Press, Minsk, 2008, $443 \mathrm{p}$.

[10] Yu. N. Gavrilenko, "Numerical Modeling of the Processes of the Earth's Surface by the Finite-Element Method in the Three-Dimensional Statement," PhysicalTechnical Problems of Rock Production, No. 3, 2001, pp. 12-25.

[11] I. I. Zelentsov, A. A. Varlamov, et al., "Report on Exploration Results on the Petrikov Potassium Deposit Potassium in the Gomel Region of BSSR with Account of the Reserves according to Commercial Categories on 1 October 1974 (Petrikov Objects 2, 3) [Text, Graphical Application],” Report/GGP-Slutsk, 1974.

[12] G. S. Pisarenko and A. A. Lebedev, "Strain and Strength of Materials in the Complex Stress State," Naukova Dumka, Kiev, 1976.

[13] K. A. Stepanov, M. A. Zhuravkov, I. S. Nevelson, et al., "Instructions for Protection of Structures and Natural Objects from the Underground Mining Influences on the Starobin Potassium Salt Deposit," Soligorsk, Belgorkhimprom, 2002, $341 \mathrm{p}$.

[14] Rules for Protection of Mines from Flood on the Starobin Potassium Salt Deposit, Minsk, 2006. 